Praveen Shukla

Awadhesh Kumar Sharma*

\section{Biswajit Majumder}

\section{Pritam Kumar} Chatterjee

\section{Vinay Krishna}

\section{Anamika Shukla}

TO DETERMINE THE ROLE OF RANOLAZINE FOR RHYTHM CONTROL STRATEGY IN PATIENTS WITH NON- VALVULAR ATRIAL FIBRILLATION- AN OBSERVATIONAL STUDY FROM A TERTIARY CARE CENTER. (RANOVA STUDY)

DM, Assistant Professor, Department of Cardiology, LPS Institute of Cardiology, Kanpur, UP, India-208019.

DM, FACC, FSCAI, Assistant Professor, Department of Cardiology, LPS Institute of Cardiology, Kanpur, UP,India-208019. *Corresponding Author

DM, Associate Professor, Department of Cardiology, RG Kar Medical College, Kolkata, WB, India-700004.

DM, Assistant Professor, Department of Cardiology, Calcutta National Medical College, Kolkata, WB,India-700004.

Mch, Professor \& director, LPS Institute of Cardiology, Kanpur, UP,India208019.

DNB Obs \& Gynecology, Resident, The Calcutta Medical Research Institute, Kolkata, West Bengal, India-700004.

\title{
ABSTRACT
}

Objectives - Non- valvular atrial fibrillation (NVAF) is the most commonly occurring arrhythmia worldwide .Ranolazine is an emerging drug with a ray of hope in the management of NVAF. This is the first large observational study with longer follow up of one year.

Methods - It is a hospital based observational prospective study. A total of 100 patients was recruited for the study. The primary objective was to determine the efficacy of ranolazine in converting NVAF to sinus rhythm \& the secondary objective was to study epidemiological aspects of NVAF.

Results -After 1 month of follow up conversion to normal sinus rhythm was $12 \%$ in group A \& $6 \%$ in group B (6\%), it was not significant statistically $(Z=1.48 \mathrm{p}=0.13$ ). After 6 months, conversion to normal sinus rhythm was increased from $12 \%$ to $18 \%$ in group A which was preserved at 12 months of follow up and statistically significant and higher than that of group B (6.0\%) $(\mathrm{Z}=2.6 \mathrm{l} \mathrm{p}=0.009)$. In predisposing risk factors \& other co-morbidities $\mathrm{HTN}$ was present in $61 \%$, obesity together with overweight in $37 \%$, smoking in $44 \%$, history of moderate amount of alcohol intake in $35 \%$, history of CVA/TIA in $13 \%, \mathrm{DM}$ in $11 \%$, CKD in $4 \%$, $\mathrm{CAD}$ in $30 \%, \mathrm{COPD}$ in $20 \%$ and congestive heart failure in $15 \%$ of the patients.

Conclusion- Ranolazine is an effective option when used for rhythm control strategy in NVAF. HTN is the predominant predisposing risk factor.

KEYWORDS : Atrial fibrillation; Ranolazine; Cardio version; Rhythm control; Anti-arrhythmic drug

\section{INTRODUCTION}

Non-valvular Atrial fibrillation (NVAF) is the most commonly occurring rhythm abnormality across the globe, and a major public health problem. ${ }^{1-3}$ Most patients with NVAF have hypertension, ischemic heart disease, cardiomyopathy, constrictive pericarditis, cardiac tumours, chronic obstructive lung disease (COPD) and obesity. The estimated global prevalence estimated to be $0.47 \%$, with significant regional variation. With the advancing age prevalence of AF increases, reaching a rate as high as $10 \%$ in octogenarians. ${ }^{4.5} \mathrm{AF}$ that terminates spontaneously or with treatment within 7 days termed paroxysmal and that persist continuously for more than 7 days called persistent. AF which is persisting for longer than 1 year and refractory to cardio version is termed as permanent AF. However, "permanent AF" is not necessarily permanent nowadays because it may be eliminated successfully by surgical or catheter ablation. Lone $A F$ is another type of $\mathrm{AF}$ that occurs in patients younger than 60 years of age in the absence of structural heart disease. This designation is very relevant because patients with lone $\mathrm{AF}$ are at lower risk of thromboembolic complications, thus eliminating the necessity for anticoagulation with warfarin or NOAC (novel oral anticoagulants). There are two electrophysiological mechanisms of AF: one or more automatic, triggered, or microreentrant foci, so-called drivers, which fire at rapid rates and cause fibrillation-like activity, and the second is multiple re-entrant circuits in the atria that, annihilate and reform wavelets, thereby perpetuating the fibrillation. Sometime both mechanisms may be present simultaneously. Several randomized controlled studies have compared a rate-control strategy with a rhythm-control strategy in patients with AF. The largest study by far was the AFFIRM study, which convincingly demonstrated that a ratecontrol strategy is better than rhythm-control strategy in asymptomatic or minimally symptomatic patients 65 years or older. While rhythm control strategy should be preferred in those having active life style, symptomatic $\mathrm{AF}$ and age less than 65 years. But there are limited available option of antiarrhythmic drugs for rhythm control strategy in view of serious side effects and sub-optimal efficacy. The first- line agents commonly used for rate control are beta-blockers and the calcium channel antagonists. For pharmacological cardio version and maintaining sinus rhythm amiodarone is the most used with a success rate of approximately $50 \%$. Recently, it has been found that ranolazine, a drug, which has been approved initially as an anti-angina drug has been shown to have antiarrhythmic properties both in experimental and clinical studies. ${ }^{6,7}$ Several case studies from western literature have shown the use of ranolazine in the treatment of atrial fibrillation, some even as a 'pill in the pocket' approach. ${ }^{8,9}$ The most important anti-arrhythmic mechanism of ranolazine is thought to be mediated by inhibiting $\mathrm{IKr}$, early $\mathrm{INa}+$, and late $\mathrm{INa}+$ currents in a selective, use-dependent way in atrial myocytes. ${ }^{10,11}$ The recent reclassification of anti-arrhythmic agents has designated drugs with this action in Class Id.

There are several large number of randomized controlled trials and meta-analysis of these trials shows that ranolazine effectively suppress the atrial fibrillation in patients with coronary artery disease, heart failure and post electrical 
cardioversion. ${ }^{12-14}$ All these studies are in favour of the role of ranolazine in suppression and cardioversion of atrial fibrillation. Though there are evidences from western literature favouring its use as a rhythm controlling agent in AF. But there is a scarcity of data from third world countries. This is the first large observational study over a broad spectrum of patient comorbidities and with longer follows up from this part of the globe investigating the role of ranolazine as a rhythm controlling agent and different epidemiological aspects in patients with non- valvular $\mathrm{AF}$.

\section{MATERIALS AND METHODS}

It is a hospital based observational prospective study done at a tertiary cardiac care centre for 1 year. A total of 100 patients were recruited for the study from both outdoor and indoor patient clinics. Determination of sample size was done using the formula, $n=z 2 p q / e 2$, here $n=$ sample size, $z=1.96$ at $95 \%$ confidence level, $\mathrm{p}=$ prevalence of atrial fibrillation i.e.1-4\% and taken maximum as $4 \% . q=(1-p)$, and $e=$ Absolute precision / margin of error (5\%). On using the formula and above values, calculated sample size was 60 . For the ease of calculations, a total sample size of 100 was taken. Each of them selected, by consecutive sampling technique. ${ }^{15}$ Patients were equally distributed into two groups without any bias for age \& sex. Thus, the patients in the two groups were in the ratio l:1. In group A, patients, were treated both Ranolazine and Rate Controlling Drugs while in group B only rate controlling drugs were used. Ranolazine used in a dose of $500 \mathrm{mg}$ twice daily in all patients. Rate controlling drugs used mainly were beta blocker i.e. metoprolol succinate in starting doses of $12.5 \mathrm{mg}$ and gradual escalation of the dose up to a maximum tolerated dose, i.e. $200 \mathrm{mg}$ per day as per rate control response of patients. Patients in whom, metoprolol were not tolerated or contraindicated, were treated with calcium channel blockers i.e. verapamil and diltiazem, mean doses used were $80 \mathrm{mg}$ and $120 \mathrm{mg}$ per day respectively. The doses of both drugs were same in two groups.

\section{Aims And Objectives Of The Study-}

The primary objective of the study was to determine the role of ranolazine for rhythm control strategy in patients with NVAF. The secondary objective was to study epidemiological aspects of $\mathrm{AF}$ in the studied population.

\section{Eligibility Criterio}

Inclusion Criteria

1. Male or non-pregnant female $>18$ years of age with non valvular AF.

2. Ability and willingness to participate based on information given to patient and to a health facility.

\section{Exclusion Criterio}

1. Patients with valvular AF.

2. Concomitant digoxin, antiarrhythmic drug ( $A \overline{A D})$ use

3. Use of potent CYP3A4 inhibitors or inducers

4. Long QT syndrome or QTc interval $\geq 500 \mathrm{~ms}$

5. ESRD requiring haemodialysis

6. Hepatic dysfunction

7. Patients those were intolerant to the drug or any adverse drug reaction.

The study was begun after due clearance from ethical committee. Patients attending Cardiology OPD and indoor satisfying the inclusion and exclusion criteria were enrolled. Detailed clinical history was taken from either patient, or attendants (in case if the patient was not able to communicate properly).Full clinical examination of patients done and recorded in predesigned schedule. Reports of blood parameter collected and reviewed. Echocardiography (2D, Mmode and Doppler) performed and results documented. Patients were put on a study directed medical therapy and followed up at 1,6 and 12 months.
Statistical Ānalysis:

Statistical analysis performed with the help of Epi Info (TM) EPI INFO is a trademark of the Centres for Disease Control and Prevention (CDC).Descriptive statistical analyses performed to calculate the means with corresponding standard deviations (SD). Test of proportion used to find the Standard Normal Deviate (Z) to compare the difference proportions and Chi-square test was performed to find the associations. In the cases, where one of the cell frequencies was less than five corrected Chi-square ( 2 ) was used to find the association between variables. Also One Way Analysis of variance (ANOVA) followed by post hoc Tukey's Test was performed with the help of Critical Difference (CD) at $5 \%$ and $1 \%$ level of significance to compare the mean values. $p<0.05$ was taken to be statistically significant.

\section{RESULT}

There was no significant difference in age and gender between Group A and Group B. The mean age of the study population in Group A and Group B was 63.98 \pm 8.6 lyears and $64.06 \pm 8.25$ years respectively (p-value 0.83 ). A total number of male subjects in both the groups were 23 (50\%) (p-value of 0.99) while the number of female subjects in both the groups was 27 ( $p$-value of 0.99). There was no significant association between socio-economic status $(p=0.99)$ and symptomatic presentation of the patients of the two groups $(p>0.05)$. [Tablel].

Tablel- Distribution Of Symptomatic Presentation Of The Patients. Ns-non-significant

\begin{tabular}{|l|l|l|l|l|l|l|}
\hline \multirow{2}{*}{ Symptoms } & Group- $\mathbf{A}$ & \multicolumn{2}{l|}{ Group-B } & Z-Values & p-values \\
\cline { 2 - 7 } & Number & $\%$ & Number & $\%$ & & \\
\hline Chest pain & 22 & $44.0 \%$ & 21 & $42.0 \%$ & 0.28 & 0.77 NS \\
\hline Palpitation & 45 & $90.0 \%$ & 47 & $94.0 \%$ & 1.04 & 0.29 NS \\
\hline Fatigue & 39 & $78.0 \%$ & 44 & $88.0 \%$ & 1.88 & $0.06 \mathrm{NS}$ \\
\hline Dyspnea & 22 & $44.0 \%$ & 24 & $48.0 \%$ & 0.56 & $0.57 \mathrm{NS}$ \\
\hline
\end{tabular}

There were no significant differences in co-morbidities and personal habits of the patients of the two groups. Thus, the patients of the two groups were well matched for their comorbidities and personal habits. [Table2].

Table 2-Distribution Of Co-morbidities \& Personal Habits Of The Patients. Ns-non-significant

\begin{tabular}{|l|l|l|l|l|l|}
\hline \multirow{2}{*}{ Co-morbidities } & Group- $\mathbf{A}$ & \multicolumn{2}{l|}{ Group-B } & p-values \\
\cline { 2 - 6 } & Number & $\%$ & Number & $\%$ & \\
\hline DM & 5 & $10.0 \%$ & 6 & $12.0 \%$ & $0.65 \mathrm{NS}$ \\
\hline HTN & 30 & $60.0 \%$ & 31 & $62.0 \%$ & $0.77 \mathrm{NS}$ \\
\hline CVA/TIA & 6 & $12.0 \%$ & 7 & $14.0 \%$ & $0.67 \mathrm{NS}$ \\
\hline CAD & 15 & $30.0 \%$ & 15 & $30.0 \%$ & $0.99 \mathrm{NS}$ \\
\hline CKD & 1 & $2.0 \%$ & 3 & $6.0 \%$ & $0.14 \mathrm{NS}$ \\
\hline COPD & 9 & $18.0 \%$ & 11 & $22.0 \%$ & $0.47 \mathrm{NS}$ \\
\hline CHF & 8 & $16.0 \%$ & 7 & $14.0 \%$ & $0.68 \mathrm{NS}$ \\
\hline Smoking & 20 & $40.0 \%$ & 24 & $48.0 \%$ & $>0.05 \mathrm{NS}$ \\
\hline Alcohol intake & 15 & $30.0 \%$ & 20 & $40.0 \%$ & $>0.05 \mathrm{NS}$ \\
\hline
\end{tabular}

There was no significant difference in mean of all the investigational parameters of the patients of the two groups. [Table3].

Table-3: Comparison Of Different Investigational Paramet ers Of The Patients Of The Two Groups. Ns-non-significant

\begin{tabular}{|l|l|l|l|l|l|}
\hline Parameters & Group & Mean & SD & t98 & p-value \\
\hline \multirow{2}{*}{ SBP (mmHg) } & A & 134.96 & 14.194 & 0.573 & $0.568 \mathrm{NS}$ \\
\cline { 2 - 5 } & B & 133.54 & 10.276 & & \\
\hline Hb\% & A & 11.902 & 1.1291 & 0.947 & $0.346 \mathrm{NS}$ \\
\cline { 2 - 4 } & B & 11.610 & 1.8650 & & \\
\hline Blood Urea (mg/dl) & A & 27.09 & 6.596 & 0.177 & $0.860 \mathrm{NS}$ \\
\cline { 2 - 4 } & B & 26.82 & 8.342 & & \\
\hline
\end{tabular}




\begin{tabular}{|l|l|l|l|l|l|}
\hline \multirow{2}{*}{$\begin{array}{l}\text { S. Creatinine } \\
\text { (mg/dl) }\end{array}$} & A & 1.3726 & 0.33979 & 1.55 & $0.124 \mathrm{NS}$ \\
\cline { 2 - 5 } & B & 1.2532 & 0.42526 & & \\
\hline \multirow{2}{*}{ S. Na+ (m mole/L) } & A & 137.70 & 3.471 & 0.919 & $0.360 \mathrm{NS}$ \\
& B & 138.38 & 3.912 & & \\
\hline \multirow{2}{*}{ S.K+(mmol/l) } & A & 4.384 & 0.4405 & 0.647 & $0.519 \mathrm{NS}$ \\
& B & 4.442 & 0.4558 & & \\
\hline \multirow{2}{*}{ TSH $(\mu \mathrm{IU} / \mathrm{mL})$} & A & 3.304 & 0.8471 & 1.93 & $0.056 \mathrm{NS}$ \\
\cline { 2 - 5 } & B & 3.698 & 1.1611 & & \\
\hline
\end{tabular}

Mean BMI in group A was 22.53 \pm 3.14 and in group B was $22.11 \pm 3.11(2=0.40, p=0.81 \mathrm{NS})$. Thus, the patients of the two groups more or less equally distributed over BMI. The patients of the two groups were matched for their pulse rate (PR) at baseline. There was no significant difference in mean baseline pulse rate (PR) among the patients of the two groups (t98 $=1.42 ; \mathrm{p}=0.16)$. On comparing the pulse rate of the patients of both groups at different time intervals on subsequent follow up, it was observed that in both groups mean pulse rate decreased significantly towards its normal range at different time interval compared to baseline. [ GroupA one way ANOVA F3,196 = 20.18; $<<0.0001$ \& Group -B one way ANOVA F3, $196=5.66 ; p<0.0001$ ). [Table 4\&5].

Table 4- Comparison Of Pulse Rate Of The Patients Of Group- $\alpha$ At Different Time Intervals

\begin{tabular}{|l|l|l|l|l|l|l|l|l|}
\hline $\begin{array}{l}\text { Pulse } \\
\text { rate } \\
\text { (PR) }\end{array}$ & \multicolumn{2}{|l|}{ At baseline } & \multicolumn{2}{|l|}{ After 1 Month } & $\begin{array}{l}\text { After 6 } \\
\text { month }\end{array}$ & \multicolumn{3}{|l|}{$\begin{array}{l}\text { After 12 } \\
\text { month }\end{array}$} \\
\cline { 2 - 9 } & $\begin{array}{l}\text { Numb } \\
\text { er }\end{array}$ & $\%$ & $\begin{array}{l}\text { Numbe } \\
\text { r }\end{array}$ & $\%$ & Number & $\%$ & $\begin{array}{l}\text { Num } \\
\text { ber }\end{array}$ & $\%$ \\
\hline Normal & 7 & 14.0 & 19 & 38.0 & 32 & 64.0 & 39 & 68.0 \\
\hline High & 43 & 86.0 & 31 & 62.0 & 18 & 36.0 & 11 & 22.0 \\
\hline $\begin{array}{l}\text { Mean } \pm \\
\text { SD }\end{array}$ & $81.28 \pm 8.43$ & $76.94 \pm 6.86$ & $73.78 \pm 6.25$ & $\begin{array}{l}71.04 \pm 5 . \\
88\end{array}$ \\
\hline
\end{tabular}

Table 5- Comparison Of Pulse Rate Of The Patients Of Group-b At Different Time Intervals

\begin{tabular}{|l|l|l|l|l|l|l|l|l|}
\hline $\begin{array}{l}\text { Pulse } \\
\text { rate } \\
\text { (PR) }\end{array}$ & \multicolumn{2}{|l|}{ At baseline } & \multicolumn{2}{|l|}{ After 1 Month } & $\begin{array}{l}\text { After 6 } \\
\text { month }\end{array}$ & \multicolumn{3}{l|}{$\begin{array}{l}\text { After 12 } \\
\text { month }\end{array}$} \\
\cline { 2 - 9 } & $\begin{array}{l}\text { Numb } \\
\text { er }\end{array}$ & $\%$ & $\begin{array}{l}\text { Numbe } \\
\text { r }\end{array}$ & $\%$ & Number & $\%$ & $\begin{array}{l}\text { Num } \\
\text { ber }\end{array}$ \\
\hline Normal & 9 & 18.0 & 9 & 18.0 & 29 & 58.0 & 39 & 68.0 \\
\hline High & 41 & 82.0 & 41 & 82.0 & 21 & 42.0 & 11 & 22.0 \\
\hline $\begin{array}{l}\text { Mean } \pm \\
\text { SD }\end{array}$ & $79.06 \pm 6.82$ & $74.66 \pm 6.68$ & $74.26 \pm 6.11$ & \multicolumn{2}{l}{$\begin{array}{l}71.14 \pm 4 . \\
85\end{array}$} \\
\hline
\end{tabular}

At baseline in both the groups all the patients had atrial fibrillation $(\mathrm{Z}=0.01 ; \mathrm{p}=0.99)$. After 1 month of follow up conversion to normal sinus rhythm was observed in $12 \%$ of the patients in group A which was higher than that of group B (6\%) but it was not significant $(Z=1.48 p=0.13)$. After 6 months, conversion to normal sinus rhythm was increased from $12 \%$ to $18 \%$ in Group-A which was significantly higher than that of Group-B (6.0\%) $(Z=2.61 p=0.009)$. $(Z=2.61 p=0.009)$. After 12 months of follow up, there was no new case of conversion to sinus rhythm in both the groups with preserved sinus rhythm in Group-A (18\%) which was significantly higher than that of Group-B (6.0\%) $(Z=2.61 p=0.009)$. [Table 6, Figure 1].

Table 6- Comparison Of Pulse Rhythm Of The Patients After 1 Month. Nsr -normal Sinus Rhythm. Af- Atrial Fibrillation, Ns-Non Significant, S- Significant

\begin{tabular}{|l|l|l|l|l|l|l|}
\hline Follow up & Rhythm & \multicolumn{2}{|l|}{ Group-A } & \multicolumn{2}{l|}{ Group-B } & P value \\
\cline { 3 - 6 } & & Number & $\%$ & Number & $\%$ & \\
\hline \multirow{2}{*}{1 month } & NSR & 6 & $12.0 \%$ & 3 & $6.0 \%$ & \multirow{2}{*}{$0.13 \mathrm{NS}$} \\
\cline { 2 - 6 } & $\mathrm{AF}$ & 44 & $88.0 \%$ & 47 & $94.0 \%$ & \\
\hline \multirow{2}{*}{6 month } & $\mathrm{NSR}$ & 9 & $18.0 \%$ & 3 & $6.0 \%$ & $0.009 \mathrm{~S}$ \\
\cline { 2 - 6 } & $\mathrm{AF}$ & 41 & $82.0 \%$ & 47 & $94.0 \%$ & \\
\hline \multirow{2}{*}{12 month } & $\mathrm{NSR}$ & 9 & $18.0 \%$ & 3 & $6.0 \%$ & \multirow{2}{*}{$0.009 \mathrm{~S}$} \\
\cline { 2 - 6 } & $\mathrm{AF}$ & 41 & $82.0 \%$ & 47 & $94.0 \%$ & \\
\hline
\end{tabular}

Figure 1- Percentage Of Patients Converted To Sinus Rhythm In Both Groups At Different Time Intervals.

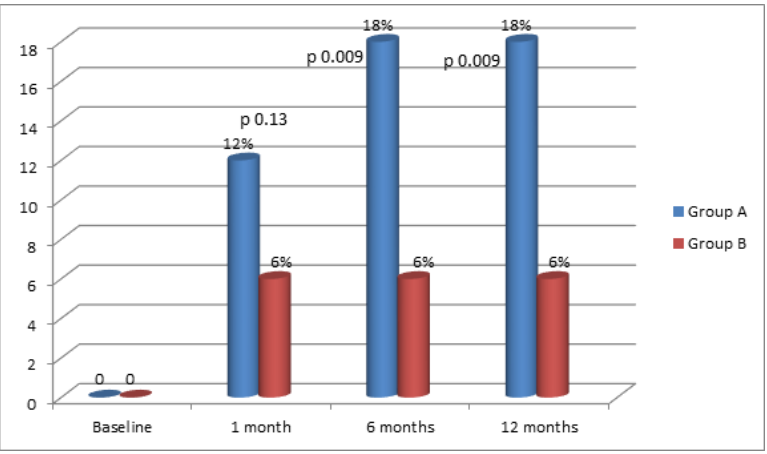

When we analyse different risk factors \& co-morbidities associated with NVAF in this part of globe, we observed that HTN was present in $61 \%$, obesity together with overweight in $37 \%$, smoking in $44 \%$, history of moderate amount of alcohol intake (two drinks a day for men, or one drink a day for women) in $35 \%$, history of CVA/TIA in $13 \%, \mathrm{DM}$ in $11 \%, \mathrm{CKD}$ in $4 \%, \mathrm{CAD}$ in $30 \%$, COPD in $20 \%$ and congestive heart failure in $15 \%$ of the patients.

\section{DISCUSSION}

Atrial fibrillation $(\mathrm{AF})$ is the most common cardiac arrhythmia and its prevalence rises with increasing age. The strategy of rhythm control is a mainstay of $\mathrm{AF}$ treatment based on available evidences but it cannot be effectively achieved without the risk of side effects such as pro arrhythmia, hypotension, or organ toxicity with current drugs. So there is an unmet need to discover a new drug based on the pathophysiology of $\mathrm{AF}$. There are reports and studies from western part of globe regarding the anti-angina late sodium current inhibitor, ranolazine, and its beneficial effects against AF. But unfortunately there is a significant lack of information regarding this from the developing nations or third world countries. There is no long-term observational study with ranolazine, which is in support of effective cardio version and persistent of sinus rhythm during follow-up in those having NVAF. This is the first observational study done in any developing country in an effort to recognize different risk factors responsible for NVAF and to see effective conversion and persistent of sinus rhythm in NVAF with ranolazine. In this study it was reported that during 12 months of treatment with ranolazine conversion to normal sinus rhythm was observed in $18.0 \%$ of the patients of Group $\bar{A}$ which was significantly higher than that of Group B $(6.0 \%)(Z=2.61 p=0.009)$. So in this study patients who are taking both rate controlling drugs and ranolazine having a higher conversion rate towards sinus rhythm as compared to patients only taking rate controlling drugs over a period of one year. $(Z=2.61 p=0.009)$. There was also a significant decline in mean pulse rate significantly towards its normal range at different time interval compared to baseline supporting the rate controlling effect of ranolazine also. Previous studies on this subject were done either on post ACS patients or post-operative patients with similar results supporting the role of ranolazine as a rhythm controlling drug. The first non-randomized retrospective cohort study, which was done by Miles et al. $(2011)^{16}$, in this he gave ranolazine to 182 and amiodarone to 211 post CABG patients. Patients who were on ranolazine had significantly fewer occurrences of post CABG AF. Tagarakis et al. $(2013)^{17}$ in a single centre randomized trial on 34 post CABG patients also had similar findings with significantly fewer occurrences of postoperative AF with ranolazine. Simopoulos et al. $(2014)^{18}$ in a single centre randomized trial on 21 post CABG AF patients concluded that combined use of ranolazine \& IV amiodarone is associated with a significantly shorter time to conversion rate in the combo group as compared to IV amiodarone alone. Similar to this Koskinas, et al. $(2014)^{8}$ concluded that in 60 patients of symptomatic patients following STEMI 
combination of ranolazine $(1500 \mathrm{mg})$ and amiodarone is associated with a significantly higher conversion rate and shorter conversion times. All these studies undoubtedly support the findings of the present study and provide a strong platform for the use of ranolazine against NVAF in third world population also. These findings are further supported by one of the earlier reports by Murdock et al. ${ }^{19}$ regarding the role of ranolazine in atrial fibrillation (AF). He reported a case series which was published in 2008 that include seven patients who developed $\mathrm{AF}$ within hours to days of ablation and / or failure of other anti-arrhythmic agents. Four of them had no recurrence of $A F$ while on ranolazine, two did not respond and one had a delayed recurrence. Inspired by his findings the same author proposed "Pill in the pocket" approach to AF using ranolazine the next year. 13 of their 18 patients converted to sinus rhythm without any proarrhythmic effects following a single dose of $2000 \mathrm{mg}$ of ranolazine. The $72 \%$ conversion rate was comparable to other reported protocols for "pill in the pocket" approach. ${ }^{20}$ The findings in our study were also on similar trends though we didn't study it for "Pill in the pocket" approach at such a higher dose. The rate of cardioversion in our study was $12 \%$ at one month, $18 \%$ at six months with no new conversion but persistence of sinus rhythm at 12 months. Though our rate of cardioversion was less as compared to case series by Murdock et al. There was an additive effect of ranolazine with amiodarone in the above studies. In our study though we didn't focus on this concept and excluded the patients on amiodarone. ${ }^{9}$ But our findings seem to be more realistic in view of large sample size as compared to previous studies. As per review of literature, ranolazine induced inhibition of peak INa in the atria, reduces atrial excitability and effective refractory period. This prevents rapid activation of the atria in AF. The blockade of $\mathrm{IKr}$ by ranolazine delays atrial repolarization thus abbreviating the diastolic interval. It is during the diastolic interval that much of the recovery of the sodium channel from drug block occurs. As a result recovery of the sodium channel from ranolazine block is impaired, resulting in a greater accumulation of the block and reduction of INa. The maintenance of a diastolic interval in the ventricle, even at rapid rapids of activation, accounts for the lesser effect of ranolazine in the ventricles when compared with the atria. Block of both peak and late sodium current by ranolazine in the atria reduces intracellular calcium activity which in turn suppresses after depolarizationmediated triggers of $A F^{11}$ In the HARMONY trial ${ }^{21}$ which was a randomized, placebo-controlled; parallel-arm study that evaluated combination of ranolazine $750 \mathrm{mg}$ twice daily and low doses of dronedarone (225 mg twice daily or $150 \mathrm{mg}$ twice daily) to 131 patients with paroxysmal $\mathrm{AF}$ and it was reported that 12 week of treatment period with the combination therapy was superior to either drug alone in reducing the burden of atrial fibrillation (AF).This trial further emphasized the role of ranolazine in cardioversion of $\mathrm{AF}$ similar to our findings in third world population. Further supporting studies in the form of randomized MERLIN-TIMI 36 Trial $^{22}$ in which the effect of ranolazine on the incidence of atrial fibrillation in patients with acute coronary syndrome was studied. New-onset atrial fibrillation was observed in lesser patients in the ranolazine group [55 (1.7\%) vs. 75 (2.4\%) in the placebo group; $p=0.08$ ]. There was no pro-arrhythmia with ranolazine therapy and there were few patients with episodes of ventricular tachycardia lasting greater than eight beats in the ranolazine group. In the present study, we observed the findings for the rate of cardiovesion between two groups in which one receiving ranolazine $(1000 \mathrm{mg})$ plus rate controlling agents and other only rate controlling agents. Both the groups were observed for 1 year with follow up at 1,6 and 12 months. At one month of follow up $12 \%$ of the patients converted to sinus rhythm in combination therapy which was clinically not significant as compared to other group receiving rate controlling drugs alone. At 6 months of follow up there was significant conversion to sinus rhythm (18\%) with combination therapy while at 12 months there was no new conversion but persistence of sinus rhythm with combination therapy. These findings were suggested that the likelihood of cardioversion is maximum up to 6 months with the perseverance of rhythm thereafter. The rate of cardiversion in other group receiving rate controlling agents was only $3 \%$ at one month of follow up with no new conversion at $6 \& 12$ months. The initial conversion to sinus rhythm in these patients was likely to be due to spontaneous cardioversion. As per literature patients with atrial fibrillation (AF) of less than 48 hours duration have a very high rate of spontaneous conversion (SC) to sinus rhythm (SR). Spontaneous conversion to sinus rhythm occurs in almost $70 \%$ of patients presenting with atrial fibrillation of $<72$-h duration. While patients with $\mathrm{AF}$ of $>48$ hour duration (range, 2 to 453 days) who were not receiving antiarrhythmic drug $16 \%$ experienced spontaneous conversion to sinus rhythm. ${ }^{23,24}$ In our study no major adverse effect of ranolazine was seen during the entire follow up period. As per different study adverse effect of ranolazine is very minimal only $4 \%$ as compared to placebo. Main adverse effects of drug are dizziness, constipation, headache and nausea. These symptoms, especially asked in follow-up visit. No patient excluded from the study, just because of the adverse effect. All patients tolerated minor adverse effects of the drug. When we review the literature from third world countries regarding epidemiological aspects of NVAF then as per different studies it was found that in India, mean age at diagnosis of NVAF is 65.8 years, and $26.3 \%$ of the patients were older than 75 years. In our study, mean age of diagnosis of non-valvular atrial fibrillation is too $64.00 \pm 8.66 \mathrm{yrs}$. Most of the patients were with age $>55$ years. Thus, based on these it can be concluded that non-valvular atrial fibrillation was most prevalent among the patients with age $>55$ years. Few studies from India have shown that the mean age of patients with $\mathrm{AF}$ is nearly a decade younger than western cohort. In a similar study hospital data records of patients with chronic AF from Andhra Pradesh, revealed a mean age of 45.4 years, with most $(51 \%)$ aged $<50$ years and only $16.3 \%$ older than 60 years. In an observational hospital based study carried amongst indoor patients of AF by Vidya et al. reported that the mean age of the patients was 47 years and the majority of patients were aged between 51-60 years (48\%). ${ }^{25,26}$ There is now greater recognition that the epidemiology of $\overline{A F}$ differs between men and women. The age-adjusted incidence of $\mathrm{AF}$ is higher in men compared to women in North American and European populations. In study by $\mathrm{KO}$, d et al. ${ }^{27}$ the incidence of $\mathrm{AF}$ was higher among men than women. Similar to western literature in Asian populations also a higher incidence of $A F$ in observed in men; although less data are available. A study by Chugh et $\mathrm{al}^{3}$ found higher incidence of $\mathrm{AF}$ among men. In GARFIELD-AF data by Jitendra PS. Sawhney et al who found that atrial fibrillation among the $40.1 \%$ in Indian women as compared to $44.2 \%$ in all other countries. ( $\mathrm{p}$ value $=0.002$ ) ${ }^{28}$ Contrary to this in our study, the incidence of non-valvular atrial fibrillation is higher among female $(54 \%)$ than male $(46 \%)$ and the prevalence was more than reported previously. This seems to be due to low threshold for a symptomatic presentation like palpitation in this part of globe as compared to the male counterpart. When we analyse different risk factors and comorbidities among NVAF in this part of globe, we observed that HTN was present in $61 \%$, obesity together with overweight in $37 \%$, smoking was present in $44 \%$, history of moderate amount of alcohol intake (two drinks a day for men, or one drink a day for women) in 35\%, history of CVA/TIA in 13\%, DM in $11 \%, \mathrm{CKD}$ in $4 \%, \mathrm{CAD}$ in $30 \%, \mathrm{COPD}$ in $20 \%$ and congestive heart failure in $15 \%$ of the patients. Hypertension was present in $61 \%$ of the patient in our study. Epidemiologic studies have shown that HTN is associated with a 1.8-fold increased risk of developing new-onset $\mathrm{AF}$ and a 1.5-fold increased risk of progression to permanent $\overline{A F}$. In some studies, up to $90 \%$ of $\overline{A F}$ patients are observed to be hypertensive. ${ }^{29}$ In the present study habit of smoking is present in $44.0 \%$. The prevalence of smoking habit is almost similar to other previous studies. In few prior studies, it was reported that smoking is associated 
with new onset AF. The FHS showed that within the last 50 years, the frequency of smoking with new-onset AF has decreased.$^{30}$ In GARFIELD-AF ${ }^{28}$, data by Jitendra PS. Sawhney smoking current /ex-smoker found among $16 \%$ of patients in India a multicentre study conducted in different cities of India. Among all other countries data smoking habit was significantly lower among Indian patients, smoking habits were as high as $34.6 \%$ as compared to India where smoking habits current/ ex-smoker was 16\%.( p-value less than 0.0001 ).In our study, a higher incidence of smoking is due to different smoking habits in rural and urban population and regional variation of smoking habits. Numerous studies have shown an association between elevated BMI and increased risk of $\mathrm{AF}^{31,32}$ A meta-analyses of five studies found that obesity had a $49 \%$ increased risk of developing AF.A dose-response relationship was observed with each 1 unit increase in BMI associated with a $3 \%-4.7 \%$ increase in AF risk. ${ }^{33,34}$ Moreover, obesity is now the second biggest attributable risk factor for $\mathrm{AF}$ after hypertension. Together with overweight, it accounted for $17.9 \%$ of all AF cases in the Atherosclerosis Risk in Communities (ARIC) study. ${ }^{35}$ In our study prevalence of obesity together with overweight is somewhat higher i.e. $37 \%$ in comparison to western counterpart, the reason behind the increased prevalence seem to genetic predisposition and unhealthy diet more so in this part of the globe. Moderate alcohol consumption was reported in $35 \%$ of the patients in our study. As per data from Norwegian HUNT (Nord-Trondel ag Health) Study among 47002 participants, although alcohol consumption was associated with an increasing risk of $\mathrm{AF}$ in general, the attributable risk of alcohol consumption within recommended limits among participants without binge or problem drinking was negligible. ${ }^{36}$ As per data from our study CVA/TIA present in $13 \%$ studied population. As per literature patients with non-valvular AF has a 5-fold excess risk of stroke. Weather stroke is due to $\mathrm{AF}$ or stroke predisposes $\mathrm{AF}$ incidence is still a matter of debate. ${ }^{37} \mathrm{CAD}$ and $\mathrm{CHF}$ were reported as an important risk factor for $\mathrm{AF}$ in our study. $\mathrm{CAD}$ was reported in $30 \%$, while CHF was in $15 \%$ of the study population. In few studies the incidence of coronary artery disease (CAD) in patients with atrial fibrillation (AF) ranged between 24 and $46.5 \%$ which was in line with our study. The majority of the prior studies of the use of ranolazine as a cardioversion drug in $\mathrm{AF}$ were done on CAD patients. ${ }^{38}$ On the other hand, in an analysis of the Framingham Heart Study, atrial fibrillation (AF) and congestive heart failure (CHF) have been found to be associated with each other, and the presence of either one increases the risk of developing the other and also increases the mortality risk associated with the other. In FHS analysis, patients who had $\mathrm{CHF}, 24 \%$ had a prior or concurrent diagnosis of $\mathrm{AF}$, and $17 \%$ developed $\mathrm{AF}$ during the follow up period of 4.2 years. ${ }^{39}$ So both CHF and AF are interrelated to each other. DM is one of the most common concomitant diseases in patients with $\mathrm{AF}$. It was present in $11 \%$ of patients in our study. The multivariate analysis showed that DM is independently associated with $\mathrm{AF}(\mathrm{OR}, 1.46) .^{40} \mathrm{COPD}$ and $\mathrm{CKD}$ are an important predisposing risk factor for NVAF. The atrial fibrillation rhythm was 1.5-2 times more frequent in COPD patients in comparison to those without COPD. In our study COPD was reported in $20 \%$ of patients. ${ }^{41}$ Similarly AF frequently complicates chronic kidney disease (CKD) which was present in $4 \%$ of the patients in present study population. $\mathrm{CKD}$ and AF share risk factors and putative mechanisms, suggesting that common pathophysiologic processes may drive both pathologies. One possible common link between $\mathrm{AF}$ and CKD is activation of the renin-angio tensin-ald ost erone system (RAAS). ${ }^{42}$

\section{Study Limitations}

This study has a few limitations. The important ones which deserve mention are outlined. First, it is a single centre study and may not be representative of the population at large. Second is that event loop recording was not done in those patients who were converted into sinus rhythm, to rule out the remote possibility of paroxysmal atrial fibrillation. And the last one is lack of blinded controls.

\section{CONCLUSION}

Ranolazine is an effective option to be used for rhythm control in NVAF in third world population also. As per study outcome predominant risk factors for non-valvular $\mathrm{AF}$ and associated co-morbidities in this part of the globe are hypertension, diabetes mellitus, chronic obstructive pulmonary disease, cerebrovascular accidents, chronic kidney disease, smoking and alcohol use. The findings in favour of ranolazine as an effective antiarrhythmic drug warrant future studies in the form of blind randomized controlled trials involving a large population across the globe with inclusion of event loop recording for rhythm monitoring.

ABBREVIATION- NVAF (Non Valvular Atrial Fibrillation), NOAC (novel oral anticoagulant), BMI (Body Mass Index), DM(Diabetes mellitus), CKD(Chronic Kidney Disease), CVA(Cerebro Vascular Accident), TIA(Transient Ischemic Attack), COPD(Chronic Obstructive Pulmonary Disease), CHF(Congestive Heart Failure), HTN(Hypertension).

\section{REFERENCES}

1. Ezekowitz MD. Atrial fibrillation: the epidemic of the new millennium. Ann Intern Med 1999;131:537

2. Lip GY, Brechin CM, Lane DA. The global burden of atrial fibrillation and stroke: a systematic review of the epidemiology of atrial fibrillation in regions outside North America and Europe. Chest2012;142:1489-98.

3. Chugh SS, Havmoeller R, Narayanan K et al. Worldwide epidemiology of atrial fibrillation: a global burden of disease 2010 study. Circulation 2014;129:837-47

4. Lloyd-Jones DM, Wang TJ, Leip EP et al. Lifetime risk for development of atrial fibrillation: the Framingham Heart Study. Circulation 2004;110:1042-6.

5. Benjamin EJ, Levy D, Vaziri SM et al. Independent risk factors for atrial fibrillation in a population-based cohort-The Framingham Heart Study. JAMA 1994;271:840

6. Antzelevitch Charles, Belardinelli Luiz, Zygmunt Andrew C, Burashnikov Alexander, Di Diego José M, Fish Jeffrey M, Cordeiro Jonathan M, Thomas George. Electrophysiological effects of ranolazine, a novel antianginal agent with antiarrhythmic properties. Circulation. 2004 Aug 24;1 10 (8):904-10. [PMC free article] [PubMed] [Google Scholar]

7. Kumar Kapil, Nearing Bruce D, Carvas Marcelo, Nascimento Bruno C G, Acar Mariana, Belardinelli Luiz, Verrier Richard L. Ranolazine exerts potent effects on atrial electrical properties and abbreviates atrial fibrillation duration in the intact porcine heart. J. Cardiovasc. Electrophysiol. 2009 Jul:20 (7):796-802. [PubMed] [Google Scholar]

8. Koskinas KC, Fragakis N, Katritsis D, Skeberis V, Vassilikos V. Ranolazine enhances the efficacy of amiodarone for conversion of recent-onset atrial fibrillation. Europace. 2014 Jul;16(7):973

9. Fragakis N, Koskinas KC, Katritsis DG, Pagourelias ED, Zografos T, Geleris P. Comparison of effectiveness of ranolazine plus amiodarone versus amiodarone alone for conversion of recent-onset atrial fibrillation. Am J Cardiol. 2012 Sep 1;110(5):673-7.

10. Rajamani Sridharan, El-Bizri Nesrine, Shryock John C, Makielski Jonathan C Belardinelli Luiz. Use-dependent block of cardiac late $\mathrm{Na}(+)$ current by ranolazine. Heart Rhythm. 2009 Nov;6 (11):1625-31. [PMC free article] [PubMed] [Google Scholar]

11. Antzelevitch Charles, Burashnikov Alexander, Sicouri Serge, Belardinelli Luiz. Electrophysiologic basis for the antiarrhythmic actions of ranolazine. Heart Rhythm. 2011 Aug;8 (8):1281-90. [PMC free article] [PubMed] [Google Scholar]

12. Scirica BM, Morrow DA, Hod H, et al. Effect of Ranolazine, an antianginal agent with novel electrophysiological properties on the incidence of arrhythmias in patients with non ST-segment elevation acute coronary syndrome: results from the metabolic efficiency with ranolazine for less ischemia in non st-elevation acute coronary syndrome thrombolysis in myocardial infarction 36 (MERLIN TIMI 36) randomized controlled trial. Circulation 2007;116:1647-52

13. Burashnikov A, Di Diego JM, Barajas-Martinez H, et al. Ranolazine Effectively Suppresses Atrial Fibrillation in the Setting of Heart Failure. Circulation: Heart Failure 2014;7(4):627-633.

14. Murdock DK, Kaliebe J, Larrain G. The use of ranolazine to facilitate electrical cardioversion in cardioversion-resistant patients: a case series. Pacing Clin Electrophysiol 2012;35:302-7

15. Lafuente-Lafuente C, Mouly S, Longa's-Tejero MA, et al. Antiarrhythmic drugs for maintaining sinus rhythm after cardioversion of atrial fibrillation:a systematic review of randomized controlled trials. Arch Intern Med 2006; 166:719-28

16. Miles RH, Passman R, Murdock DK. Comparison of effectiveness and safety of ranolazine versus amiodarone for preventing atrial fibrillation after coronary artery bypass grafting. Am J Cardiol. 2011;108(5):673-6.

17. Tagarakis GI, Aidonidis I, Daskalopoulou SS, et al. Effect of ranolazine in preventing postoperative atrial fibrillation in patients undergoing coronary revascularization surgery. Curr Vasc Pharmacol. 2013;1 1 (6):988-91

18. Simopoulos V, Tagarakis GI, Daskalopoulou SS, Daskalopoulos ME, Lenos A, Chryssagis K, Skoularingis I, Molyvdas PA, Tsilimingas NB, Aidonidis I. Ranolazine enhances the antiarrhythmic activity of amiodarone by 
accelerating conversion of new-onset atrial fibrillation after cardiac surgery. Angiology. 2014 Apr;65(4):294-7.

19. Murdock DK, Overton N, Kersten M, Kaliebe J, Devecchi F. The effect of ranolazine on maintaining sinus rhythm in patients with resistant atrial fibrillation. Indian Pacing Electrophysiol J. 2008 Aug 1;8(3):175-81.

20. Murdock DK, Kersten M, Kaliebe J, Larrain G. The use of oral ranolazine to convert new or paroxysmal atrial fibrillation: a review of experience with implications for possible "pill in the pocket" approach to atrial fibrillation. Indian Pacing Electrophysiol J. 2009 Sep 1;9(5):260-7.

21. Reiffel JA, Camm AJ, Belardinelli L, et al. The HARMONY Trial -- Combined Ranolazine and Dronedarone in the Management of Paroxysmal Atrial Fibrillation: Mechanistic and Therapeutic Synergism. Circ Arrhythm Electrophysiol 2015;8:1048-1056

22. Morrow DA, Scirica BM, Karwatowska-Prokopczuk E, et al. Effects of Ranolazine on Recurrent Cardiovascular Effects in Patients With Non-STElevation Acute Coronary Syndromes, The MERLIN-TIMI 36 Randomized Trial. JAMA 2007;297:1775-1783

23. Danias PG, Caulfield TA, Weigner MJ, Silverman DI, Manning WJ. Likelihood of spontaneous conversion of atrial fibrillation to sinus rhythm. J Am Coll Cardiol. 1998:31(3):588-592. doi:10.1016/s0735-1097(97)00534-2

24. Tejan-Sie SA et al. for the ACUTE Investigators. Spontaneous conversion of patients with atrial fibrillation scheduled for electrical cardioversion: An ACUTE Trial ancillary study. J Am Coll Cardiol 2003 Nov 5; 42:1638-43.

25. Rao VD, Reddy RM, Srikanth $\mathrm{K}$ et al. To Study The Prevalence And Clinical Profile of Chronic Atrial Fibrillation In Hospitalized Patients. NUJHS 2014; 4.

26. Vidya N, Gupta AK, Mahmood et al.Etiological Profile and Clinical Presentation of Patients with Atrial Fibrillation from a Rural Area of Bihar. Nat J Clin Med Res 2012; 2;124-127.

27. Ko D, Rahman F, Schnabel RB et al. Atrial fibrillation in women: epidemiology, pathophysiology, presentation, and prognosis. Nat Rev Cardiol. 2016

28. Jitendra PS. Sawhney $a,{ }^{*}$, Veerappa A. Kothiwale b et al. .Risk profiles and one-year outcomes of patients with newly diagnosed atrial fibrillation in India: Insights from the GARFIELD-AF Registry

29. Patel MR, Mahaffey KW, Garg J et al. Rivaroxaban versus warfarin in nonvalvular atrial fibrillation. N Engl J Med. 2011 Sep 8;365(10):883-91. ROCKET AF Investigators. [PubMed] [Google Scholar]

30. Schnabel RB, Yin $\mathrm{X}$, Gona $\mathrm{P}$, et al. 50 year trends in atrial fibrillation prevalence, incidence, risk factors, and mortality in the Framingham Heart Study: a cohort study. Lancet. 2015; 386:154-62.

31. Murphy NF, MacIntyre $\mathrm{K}$, Stewart $\mathrm{S}$ et al. Long-term cardiovascular consequences of obesity: 20-year follow-up of more than 15000 middle-aged men and women (the Renfrew-Paisley study). Eur Heart J. 2006; 27:96-106.

32. Wanahita N, Messerli FH, Bangalore $S$ et al. Atrial fibrillation and obesityresults of a meta-analysis. American heart journal. 2008; 155:310-5.

33. Tedrow UB, Conen D, Ridker PM et al. The long- and short-term impact of elevated body mass index on the risk of new atrial fibrillation the WHS (women's health study). J Am Coll Cardiol. 2010; 55:2319-27.

34. Gami AS, Hodge DO, Herges RM et al. Obstructive sleep apnea, obesity, and the risk of incident atrial fibrillation. J Am Coll Cardiol. 2007; 49:565-71.

35. Huxley RR, Lopez FL, Folsom AR et al. Absolute and attributable risks of atrial fibrillation in relation to optimal and borderline risk factors: the atherosclerosis risk in communities (ARIC) study. Circulation. 2011; 123:1501 -8. doi: 10.1161/CIRCULATIONAHA.110.009035. [PMC free article] [PubMed] [CrossRef] [Google Scholar]

36. Katalin Gémes, Vegard Malmo, Lars Erik Laugsand et al. Does Moderate Drinking Increase the Risk of Atrial Fibrillation? The Norwegian HUNT (Nord-Trøndelag Health) Study. J Am Heart Assoc. 2017; 6:e007094. DOI: 10.1161/JAHA.117.007094

37. Hart RG, Halperin JL. Atrial fibrillation and stroke: concepts and controversies. Stroke. 2001; 32: 803-808.

38. Kralev S, Schneider K, Lang S, Süselbeck T, Borggrefe M. Incidence and severity of coronary artery disease in patients with atrial fibrillation undergoing first-time coronary angiography. PLoS One. 2011;6(9):e24964. doi:10.1371/journal.pone.0024964

39. Wang TI, Larson MG, Levy D, et al. Temporal relation of atrial fibrillation and congestive heart failure and their joint influence on mortality: the Framingham Heart Study. Circulation 2003; 107:2920.

40. Iguchi Y, Kimura K, Aoki J, et al. Prevalence of atrial fibrillation in communitydwelling Japanese aged 40 years or older in Japan: analysis of 41,436 nonemployee residents in Kurashiki-city. Circ J. 2008 Jun;72:909-13.

41. Liao KM, Chen CY. Incidence and risk factors of atrial fibrillation in Asian COPD patients. Int J Chron Obstruct Pulmon Dis. 2017;12:2523-2530. Published 2017 Aug 23. doi:10.2147/COPD.S143691

42. Kiuchi MG. Atrial fibrillation and chronic kidney disease: A bad combination. Kidney Res Clin Pract. 2018:37(2):103-105. doi:10.23876/j.krcp.2018.37.2.103 